\title{
Otimização de simulação didática para facilitar a assimilação de conceitos de Target Costing/Target Value Design
}

\author{
Felipe de Castro*, Ariovaldo D. Granja.
}

\section{Resumo}

O trabalho se baseia na otimização do "Marshmallow Game", que é uma simulação com a meta de transmitir didaticamente os conceitos sobre "Target Costing "e "Target Value Design". Deste modo, a partir de quatro aplicações do jogo, com início no modelo original e com conclusão no modelo proposta pelo autor, gerou-se uma nova simulação, a qual é mais coerente com a realidade e permite uma melhor comparação dos resultados.

\section{Palavras-chave}

Target Costing, Target Value Design, Marshmallow Game.

\section{Introdução}

O "Marshmallow Game" é uma simulação didática que tem como objetivo transmitir os conceitos de "Target Costing" e "Target Value Design" para estudantes e profissionais. Assim, os projetos elaborados pelo público alvo geram produtos de melhor desempenho e com custos inferiores aos atuais.

Portanto, o objetivo deste trabalho é otimizar o "Marshmallow Game", de modo que a simulação absorva novos elementos da realidade e se torne ainda mais didática.

\section{Resultados e Discussão}

A metodologia de pesquisa se baseou, inicialmente, na leitura da literatura. Em seguida, aplicouse o modelo original do "Marshmallow Game" para estudantes da pós-graduação nas áreas de Engenharia Civil, Arquitetura e Urbanismo. Ele se baseia em requerer que duas equipes com quatro pessoas, as quais devem conter dois membros designados como construtores, enquanto que os outros dois membros atuam como projetistas. O objetivo do jogo é as equipes construírem um protótipo, com os materiais disponibilizados, de forma a atender os requisitos de altura e desempenho. $\mathrm{Na}$ primeira etapa, as equipes atuam em modelo tradicional de projeto, que é caracterizado pela falta de interação entre construtores e projetistas. A etapa seguinte envolve os mesmos elementos, mas com a interação das equipes, além da definição de um custo-meta para o protótipo. Assim, o autor absorveu os conceitos da simulação.

Após a etapa anterior, aplicou-se uma nova simulação, mas com alterações propostas. Essas mudanças envolveram a aplicação simultânea das etapas, de modo que uma equipe atuasse em modelo tradicional, enquanto que a outra equipe trabalhasse em modelo colaborativo ("Integrated Project Delivery"). Ressalta-se ainda que a equipe em modelo tradicional teve acesso aos custos dos materiais apenas após a primeira entrega do projeto para os projetistas. Assim, como ambas as equipes tinham um limite de custo (o qual era disponibilizado para a equipe em modelo tradicional também apenas após a primeira entrega), era comum que o projeto retornasse aos projetistas inúmeras vezes no modelo tradicional. O público alvo nesta etapa foram os estudantes de graduação também dos cursos de Engenharia Civil, Arquitetura e Urbanismo.
Como resultado das duas primeiras aplicações da simulação "Marshmallow Game" (modelos original e proposto), elaborou-se um modelo final para a simulação, o qual foi aplicado mais duas vezes: primeiro novamente para estudantes de graduação e, em seguida, para estudantes de pós-graduação.

As alterações finais propostas foram:

- Aplicação simultânea das etapas para equipes diferentes;

- O protótipo é avaliado em função de respeitar o custo estipulado, além de apresentar o máximo volume possível (o qual é calculado de maneira aproximada em casos que não ocorra diferença visual).

Os principais resultados são apresentados a seguir:

- Melhor comparação dos resultados, de forma a comprovar que o modelo colaborativo gera produtos mais baratos e com melhor desempenho;

- Melhor administração do tempo por parte da equipe que trabalha em modelo colaborativo;

- Comprovação que o modelo colaborativo gera soluções criativas e de alto desempenho para o produto final.

\section{Conclusões}

Através dos resultados deste trabalho, é possível concluir que o "Marshmallow Game", segundo o novo modelo proposto, torna-se mais coerente com a realidade de empresas que atuam no setor de construção civil. Além disso, a simulação comprova que o modelo colaborativo gera resultados para o produto final, em termos de desempenho e custo, melhores do que o modelo tradicional.

\section{Agradecimentos}

Agradeço aos inúmeros conselhos que meu orientador e sua equipe me deram ao longo de todo o projeto.

Agradeço ao Procad (CAPES) por fomentar minha pesquisa com seu auxílio financeiro.

\footnotetext{
' Munankami, M. B.; Rybkowski, Z.K.; Thesis, 2012, 108.

Oliva, C.A.; Granja, A.D.; Dissertação (mestrado) - UNICAMP. 2014, 154
} 